To be presented at the MT-13 Conference, September 20-24, 1993

Victoria Conference Centre Victoria, B.C. Canada

Conf-930926-.34

BNL -49348

\title{
Test of Eight Superconducting Arc Quadrupoles for RHIC
}

P. Wanderer, M. Anerella, G. Ganetis, M. Garber, A. Ghosh, A. Groene, R. Gupta, A. Jain, S. Kahn, E. Kelly, G. Morgan, J. Muratore, A. Prodell, M. Rehak, E. P. Rohrer, W. Sampson, R. Shutt, R. Thomas, P. Thompson, E. Willen

RHIC Project, Brookhaven National Laboratory, Upton, N.Y. 11973 U.S.A.'

Abstract-Test results from a group of eight superconducting quadrupoles made at Brookhaven National Laboratory are presentod. The magnets have been designed for use in the are regions of the Relativistic Heavy Ion Collider now under construction at Brookhaven. Novel features of the design include a single-layer cill, the use of injection-molded phenolic for the pole spacers, and a yoje that also serves as a collar. This RED series has been used to verify the magnet quench performance and field quality prior to the stant of the produclion run in industry.

\section{INTRODUCTION}

The Relativistic Heavy lon Collider (RHIC) will be a colliding beam facility with design energy of $100 \times 100$ Geviu for ions as heavy as Au. The ares will contain 276 quadrupoles of $80 \mathrm{~mm}$ aperture, $1.11 \mathrm{~m}$ magnetic length, and a design gradient of $71 \mathrm{~T} / \mathrm{m}$ at the design current of $5 \mathrm{kA}$. In addition, the insertion regions contain 144 additional 80 $\mathrm{mm}$ quadrupoles with lengths ranging from 0.93 to $1.81 \mathrm{~m}$.

Before beginning quadrupole production at Grumman Aerospace Corporation, it was decided to verify the design with a set of eight magnets made at BNL. This note summarizes the quench performance of the eight magnets and compares the field quality at room temperature $(I=10 A)$ and $4.35 \mathrm{~K}(I=3 \mathrm{kA})$. A report on a subset of these magnets, including details of the design, ends, and saturation, has recently been presented [1].

\section{MAGNET CONSTRUCTION}

A cross section of the magnet is shown in Fig. 1. The single-layer magnet coil has 16 turns and a symmetric copper wedge. For reasons of cconomy, the design uses many features of the dipole design, including the 30-strand cable with all-Kapton [2] insulation [3], an injection-molded phenolic spacer between the coil and yoke, and a two-piece yoke with a tapered midplane and borizontal split. The yoke laminations are $6.35 \mathrm{~mm}$ thick, with an inner diameter of $109.2 \mathrm{~mm}$ and an outer diameter of $266.7 \mathrm{~mm}$. Steel keys are used in the yoke.

An internally pressurized mandrel was used to seat the coils and insulators during assembly. Axial preload was applied to the magnets with set screws, which pressed against the $19 \mathrm{~mm}$-thick stainless steel end plates.

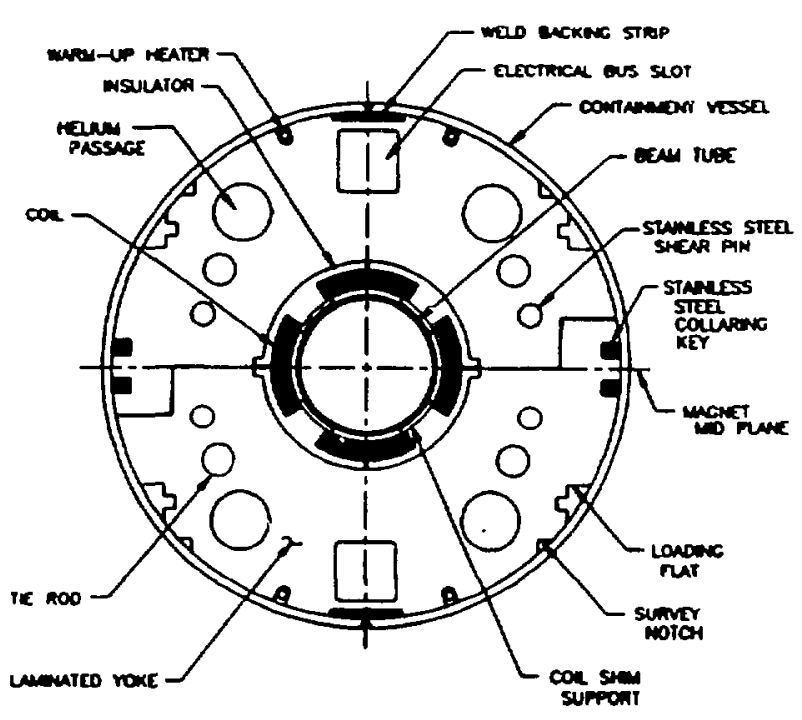

Figure 1. Cross section of QRB quadrupole cold mass.

The coils for these magnets were all made from the same spool of cable and were sorted after curing to minimize the variation in azimuthal size for a given magnet. Within a single magnet, the azimuthal size variation (largest - smallest) was $40 \mu \mathrm{m}$ at most, averaging $16 \mu \mathrm{m}$. Averaging over each magnet, the difference betwoen the smallest and largest mean azimuthal size was $80 \mu \mathrm{m}$ [4]. Assembly shims, placed between the poles and coils, were the same thickness in all the magnets.

\section{QUENCH PERFORMANCE}

A plot summarizing the quench testing of the eight magnets is shown in Fig. 2. The magnets trained in two to six quenches to tho conductor limit. No magnet quenched below $6 \mathrm{kA}, 20 \%$ over the operating curreat. At the conductor limit the queach current was about $10 \%$ greater than the value calculatod from short-sample measurements (I).

\section{FIELD QUALTTY}

For these magnets, the horizontal and vertical field components, $B_{x}$ and $B_{y}$, throughout the magnet aperture are given in polar coordinates $(r, \theta)$ by

'Work performed under Contract No. DE-ACO2-76CH00016 with the U.S. Department of Energy. 


$$
B_{y}+i B_{x}=10^{-4} B(R) \sum_{n=0}^{\infty}\left(b_{n}^{\prime}+i a_{n}^{\prime}\right)(\cos n \theta+i \sin n \theta)\left[\frac{r}{R}\right]
$$

where $i$ is the imaginary unit and $B(R)$ is the magnitude of the field due to the fundamental at the reference radius. In a normal quadrupole, $b_{i}^{\prime}=10^{+}$and $B(R)=G R$ where $G$ is the gradient $\partial B_{y} / \partial x$ at the magnet center. It is conventional to refer to the coefficients evaluated at a radius of $25 \mathrm{~mm}$ and scaled by 10\%/GR as (dimensionless) "units." The data reported here are integrals over the magnet length at $10 \mathrm{~A}$ (at room temperature) and $3 \mathrm{kA}$ (at $4.35 \mathrm{~K}$ ). The measuremeats have been corrected for feeddown effects by assuming that the magnet has zero dipole term along its axis. The uncertainty in the magnitude of the harmonics is estimated to be 5\%. The uncertainty in the integral of the quadrupole field is estimated to be at the $1 \%$ level.

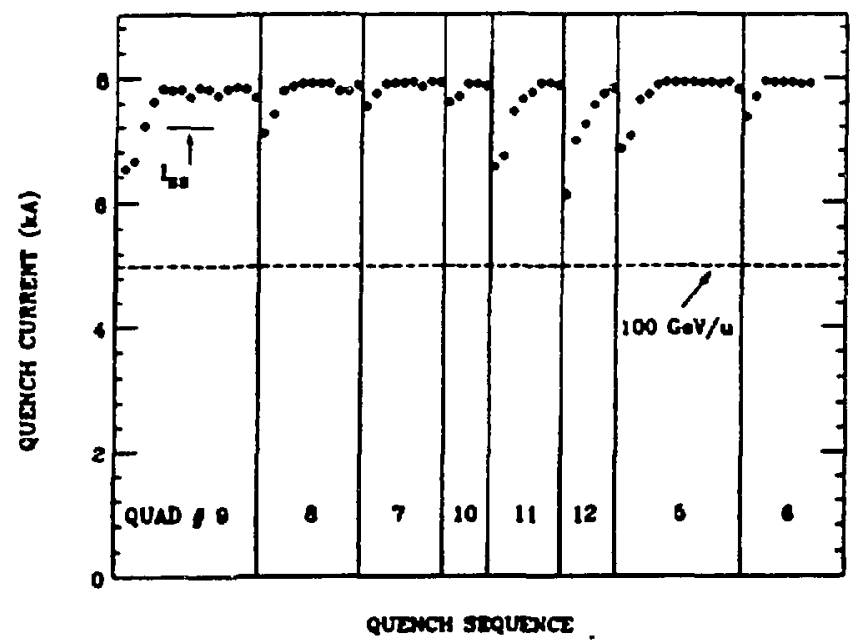

Figure 2. Quench performance of QRB quadrupoles at $4.35 \mathrm{~K}$ ramped at $83 \mathrm{~A} / \mathrm{soc}$.

Measurements of the lowest order terms are reported in Fig. 3 and in Table I. The figure shows the correlation of the room temperature and $4.35 \mathrm{~K}$ measurements. The correlation is of particular intenst because it is planned that only a small fraction of the mugnets will be cold-tested, to reduce the cost of testing. The figure is scaled so that the borizontal and vertical axes have the anme scale. Harmonics that have the same valu; warm and cold, with no measurement error, would lie on the solid $45^{\circ}$ line. Values for many of the harmonics $(n=2,3)$ fit this model. Warm and cold values for the lowest-order allowed term, $n=5$, are well-correlated but do not lie on the solid line because there is a small change of shape during the cooldown of the magnet.

The same measuring coil was used for warm and cold measurements. Its radius, sized for cold measurements inside a "warm finger", reduced the strength of signals from the highest order terms, making the warm-cold correlations worse. Nonetheless, warm and cold measurements of the second allowed term $(n=9)$ are still correlated at the level of 0.05 units [5].

At $3 \mathrm{kA}$, the effective length was measured to be 1.0973 $\pm .0002 \mathrm{~m}$; the design value is $1.020 \mathrm{~m}$. The harmonics at $3 \mathrm{kA}$ are given in Table 1 . There is generally good agreement with the calculatod values, which include not only the allowed terms $b_{5}$ and $b_{3}$ but also $b_{3}, b_{3}$, and as. The $b_{3}$ and $b$, terms are preseat due to small distortions in the yoke, which has dipole (but not quadrupole) symmetry. The as term is duc to the magnet leads which exit at the pole and run parallel to the magnet leagth for everal $\mathrm{cm}$. In magnets of this length, minimizing the harmonics due to the coil ends and leads is an essential part of optimixing the field quality.

Table I. Average Quadrupole Integral Harmonics Calculated and Measured for QRB007-012 at $3 \mathrm{kA}$ up ramp.

\begin{tabular}{|c|c|c|c|c|}
\hline n & b, Calc & b. meas & $\sigma b_{1}$ & units \\
\hline 2 & 0 & -1.35 & 1.42 & $\mathrm{~b}_{2}^{\prime}$ \\
\hline 3 & 9.3 & 7.08 & 0.66 & $\overline{b_{3}^{\prime}}$ \\
\hline 4 & 0 & 0.62 & $\overline{0.54}$ & $\overline{\mathbf{b}_{4}^{\prime}}$ \\
\hline 5 & -0.23 & 2.54 & 0.69 & $b_{3}^{p}$ \\
\hline 6 & 0 & -0.07 & $\overline{0.07}$ & $b_{6}$ \\
\hline 7 & 0.05 & 0.18 & 0.05 & $\overline{b_{7}^{\prime}}$ \\
\hline 8 & 0 & .0 .14 & $\overline{0.06}$ & $b_{t}^{\prime}$ \\
\hline 9 & -1.02 & -1.15 & $\overline{0.04}$ & $\overline{b_{?}^{\prime}}$ \\
\hline n & a Calc & 2. meas & $\sigma a$ & units \\
\hline 2 & 0 & $-1,64$ & $\overline{2.21}$ & $\mathbf{a}_{2}^{\prime}$ \\
\hline 3 & 0 & 0.08 & $\overline{0.65}$ & $a_{j}^{\prime}$ \\
\hline 4 & 0 & 2.83 & 0.48 & $a_{4}^{\prime}$ \\
\hline 5 & -1.6 & -3.65 & 0.21 & $a_{j}^{\prime}$ \\
\hline$\overline{6}$ & 0 & $\overline{0.15}$ & 0.14 & 4 \\
\hline 7 & 0 & -0.02 & 0.11 & $a_{1}^{\prime}$ \\
\hline 8 & $\overline{0}$ & 0.06 & 0.08 & $a^{\prime}$ \\
\hline 9 & 0.02 & 0.35 & $\overline{0.03}$ & 9 \\
\hline
\end{tabular}

On the basis of calculations and warm measurements, a method has been identified to reduce $b_{3}$ in production magnets. As initially built, the midplane half gaps between the coils were $0.1 \mathrm{~mm}$ thick due to the presence of the coilto-coil insulation. One magnet (QRB012) was rebuilt with the midplane half gaps doubled, to $0.2 \mathrm{~mm}$, on the horizontal midplane only. This reduced $b_{3}$ from 6.5 units to -0.9 units.

The increased thickness of the half gap generated two other harmonics of interest. The normal dodecapole $b_{s}$ 


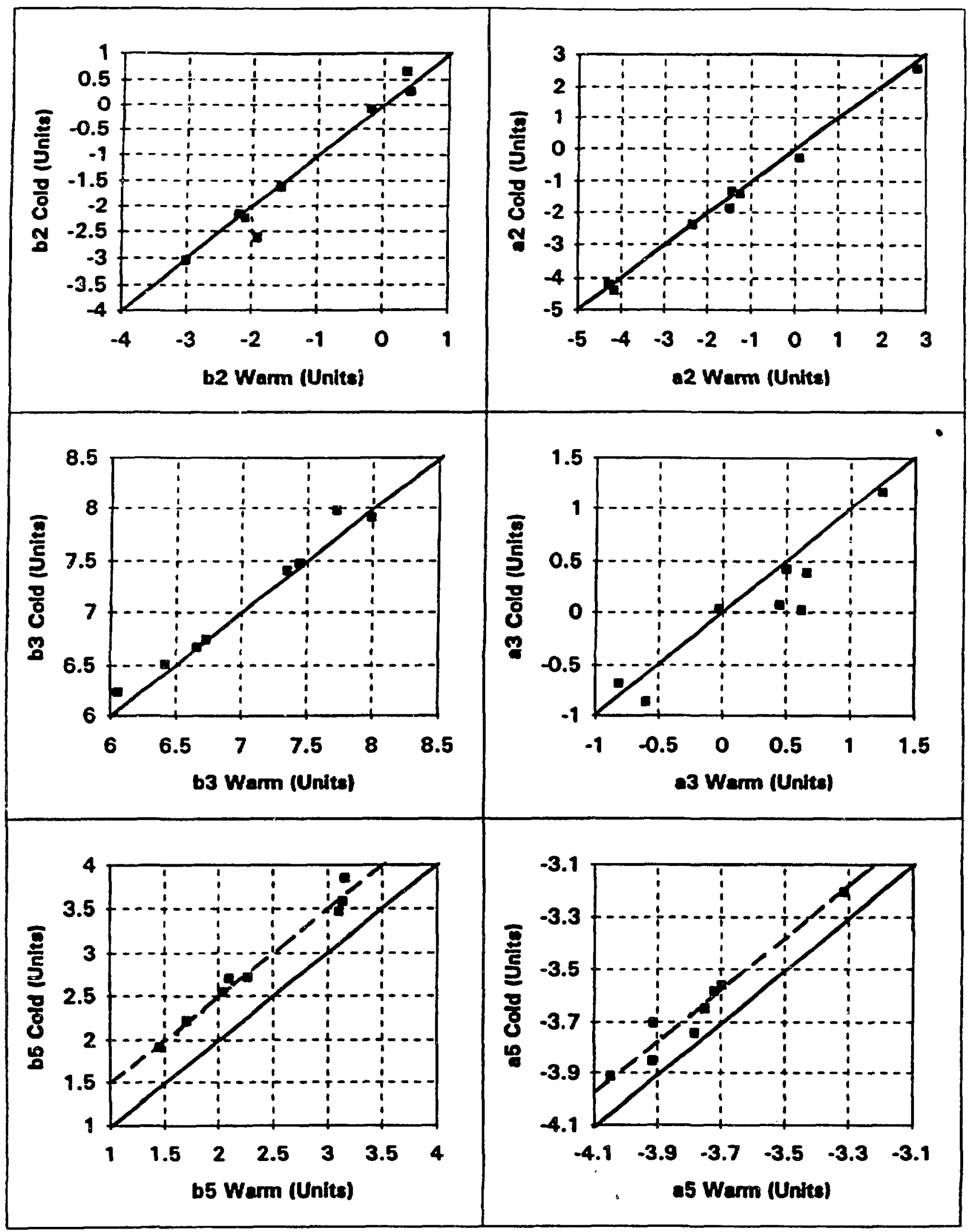

Figure 3. Correlation of the warm (10 A) and cold $(3 \mathrm{kA})$ harmonics. The dath would lie on the solid line if the two measurements were identical. 
increased 3.0 units. To obtain 2 value for $b_{3}$ in the production magnets at an acceptable level, the size of the wedge was changed. Also, the magnitude of $b_{7}$ increased from 0.05 to -0.71 units. This value is receptable.

The need for confirming calculations with magnet tests was indicated by the results of a previous shimming experiment which involved the assembly shims. Normally, the eight shims all have the same thickness. As a test, the four shims on the sides of the poles facing the horizontal midplane of the magnet were made thicker than the four shims on the sides of the poles facing the vertical axis. A calculation which assumed that the phenolic pole was rigid indicated that this should have reduced $b$, by about 7 units and $b_{s}$ by 1.7 units. However, when tried in a magnet (QRB009), $b_{3}$ decreased only 0.4 units, although $b_{3}$ did change as expected. The fact that $b_{3}$ did not change indicates that the modulus of the collas is comparable to that of the coil.

The harmonics of these magnets are being used as those expected for the production run of magnets, except for the anticipaled reduction in $b_{3}$ and $b_{5}$ noted above. These "expected" values are now used in the computer beamtracking models of RHIC. Also, it is interesting to note that the r.m.s. variation of these harmonics is essentially the same as for the production run of the two-layer quadrupoles for HERA.

\section{REFERENCES AND FOOTNOTES}

[1] P. Thompson et al., "B Series RHIC Arc Quadrupoles," 1993 Particle Accelerator Conference, May 17 - 20, 1993 (io be publishod).

[2] Kapton is a registered trademark of the Dupont Corporation.

[3] M. Anerella, A. K. Ghosh, J. Schmalzle, E. Willen, Improved Cable Insulation for Superconducting Maguets," 1993 Particle Accelerator Conference, Weshington D.C., May 17-20, 1993 (to be published).

[4] J. Schmalzle, "RHIC $8 \mathrm{~cm}$ Quadrupole Magnets QRB005-12 Summary of Construction Details," BNL RHIC Magnet Division Note 489-7 (RHIC-MD-193), March, 1993 (unpublished).

[5] A measuring coil with better sensitivity will be available in production.

\section{DISCLAIMER}

This report was prepared as an account of work sponsored by an agency of the United States Government. Neither the United States Government nor any agency thereof, nor any of their employees, makes any warranty, express or implied, or assumes any legal liability or responsibility for the accuracy, completeness, or usefulness of any information, apparatus, product, or process disclosed, or represents that its use would not infringe privately owned rights. Reference herein to any specific commerciall product, process, or service by trade name, trademark, manufacturer, or otherwise does not necessarily constitute or imply its endorsement, recommendation, or favoring by the United States Government or any agency thereof. The views and opinions of authors expressed herein do not necessarily state or reflect those of the United States Government or any agency thereof. 